\title{
Early molecular markers predictive of dengue hemorrhagic fever
}

\author{
CARlos E. CALZAVARA-SILVA ${ }^{1 *}$, ANA L.V. GOMES ${ }^{1 *}$, RITA C.C. MAIA ${ }^{3}$, \\ BARTOLOMEU ACIOLI-SANTOS ${ }^{1}$, LAURA H.V.G. GIL $^{1}$ and ERNESTO T.A. MARQUES Jr. ${ }^{2}$ \\ ${ }^{1}$ Laboratório de Virologia e Terapia Experimental, Centro de Pesquisa Aggeu Magalhães, CPqAM/FIOCRUZ \\ Av. Professor Moraes Rego, s/n, Cidade Universitária, 50670-420 Recife, PE, Brasil \\ ${ }^{2}$ Department of Medicine, Division of Infectious Diseases, Department of Pharmacology and Molecular Sciences \\ The Johns Hopkins School of Medicine, 725 North Wolfe Street, Biophysics Bld., Baltimore, MD 21205, USA \\ ${ }^{3}$ Departamento de Medicina Veterinária, Universidade Federal Rural de Pernambuco \\ Rua Francisco Lacerda, 410, Bloco 5, Várzea, 50741-150 Recife, PE, Brasil
}

Manuscript received on August 11, 2008; accepted for publication on July 9, 2009

presented by JERSON L. SILVA

\begin{abstract}
The management of acute dengue patients during outbreaks is a challenging problem. Most of the dengue fever cases are benign, but some cases develop into a severe and possibly lethal vasculopathy, known as dengue hemorrhagic fever. Early symptoms of dengue and hemorrhagic fever are very similar. An early differential diagnosis is needed to predict which of these two clinical presentations is crucial to proper patient care and public health management. This study evaluates the predictive potential of specific mRNA expression markers of dengue hemorrhagic fever using quantitative real-time PCR assays. Six candidate "dengue hemorrhagic fever specific signature genes" were evaluated and all showed good correlation among their transcription levels at early days of infection and the later development of severe vasculopathy. The markers selected were able to indicate, at early stages of infection, the evolution of a dengue-infected patient to the severe form of the illness. Despite the fact that these results grant further validation studies, the panel of candidate prognostic markers obtained demonstrated the potential to be useful for clinical use in the form of a fast assay based in blood samples.
\end{abstract}

Key words: real-time PCR, dengue hemorrhagic fever, molecular markers.

\section{INTRODUCTION}

Dengue is an acute febrile illness that has a large clinical spectrum, ranging from unapparent infection, flulike mild undifferentiated fever and the classical dengue fever (DF) to the severe disease plasma-leakage syndrome known as dengue hemorrhagic fever (DHF) (Lee et al. 2006). The impact of dengue infection in public health and on the overall economy is not well defined,

\footnotetext{
*These authors contributed equally in this work. Correspondence to: Carlos Eduardo Calzavara-Silva Present address: Laboratório de Imunologia Celular e Molecular, Centro de Pesquisas René Rachou, CPqRR/FIOCRUZ, Av. Augusto de Lima, 1715, Barro Preto, 30190-002 Belo Horizonte, MG, Brasil. E-mails: calzavara@cpqam.fiocruz.br / calzavara@cpqrr.fiocruz.br
}

but it can be considered to be very high mainly in developing countries (Shu and Huang 2004).

In the last years, we have been witnessing an increasing amount of knowledge concerning dengue. However, molecular aspects of the immune response triggered by dengue virus infection and pathogenesis of the severe form of dengue are poorly understood (Sanches et al. 2005) owing to the lack of natural animal models that develop the disease (Bente and RicoHesse 2006). DHF most often occurs in sequential dengue infection (Halstead et al. 1983). This is probably due to antibody mediated enhancement and the occurrence of abnormal immune responses against high levels of viremia and circulating antigens, resulting in 
an exacerbated production of cytokines, activation of T-lymphocytes and insufficient clearance of apoptotic bodies. The correlation of disease severity with molecular markers of immune activation and other factors such as altered platelet, dendritic cells and monocytes counts, have suggested that immune responses of dengue viruses are contributing to autoimmune process that results in DHF (Halstead 2007).

There are currently no vaccines nor antiviral drugs available for dengue viruses and neither specific therapy for the prevention and treatment of the infection caused by dengue virus. However, early diagnostic and intervention with simple medical care, like hydration, is effective to significantly reduce the dengue mortality (Sanches et al. 2005, Shu and Huang 2004).

One of the problems associated with dengue patient management is the early identification of which patients will develop DHF and will require hospitalization (Shu and Huang 2004). The diagnosis of dengue virus infection is relatively simple and trustable, but the reliable prediction of which patients will develop severe vasculopathy and DHF is not currently possible. The diagnosis is usually made after the patients had already presented severe DHF symptoms. Therefore, a rapid differential DF/DHF diagnosis is crucial to proper patient triage. A prognosis test that allows foreseeing which patients will develop DHF during the acute febrile phase of the infection could permit the focus of the medical attention to be those patients identified as under high risk to develop the lethal disease and reduce unnecessary costly hospitalizations.

The development of genomics technology, microarray and high throughput quantitative PCR has allowed the study of all the transcriptomes and develop useful tools for the investigation of the simultaneous expression and interaction of thousands of genes. The comparison of the transcriptomes of patients that developed DF with those that developed DHF has provide an opportunity to identify molecular markers associated with immunity and symptomatology of the disease (Ubol et al. 2008, Kruif et al. 2008).

Here we investigate patterns of six differentially expressed innate immune response genes in DF and DHF quantified by quantitative real-time PCR (qPCR) previously identified by DNA microarray assays and putatively candidates for molecular markers predictive of the hemorrhagic fever.

\section{MATERIALS AND METHODS}

\section{PATIENTS}

The study was performed on patients from an ongoing dengue cohort study carried out in Recife-Brazil (Cordeiro et al. 2007), approved by the local (68/02) and National Ethics Committee (4909). We used peripheral blood mononuclear cells (PBMCs) of sixteen patients with different dengue clinical forms (eight DF and eight DHF) in acute phase, and five samples obtained from health non-dengue (ND) individuals. Patients were classified following the World Health Organization (WHO) criteria. Cases that did not fitted in DF or DHF criteria were classified as dengue fever with complications (DFC). Table I shows the patients characteristics.

TABLE I

Samples used in the qPCR assays.

\begin{tabular}{c|c|c|c|c|c}
\hline Sample ID & Pathology & Age & DPO & Infection & Sex \\
\hline 588 & DF & 26 & 5 & P & M \\
\hline 659 & DF & 32 & 8 & S & F \\
\hline 650 & DF & 58 & 8 & S & F \\
\hline 620 & DF & 62 & 8 & S & M \\
\hline 600 & DF & 52 & 8 & S & M \\
\hline 677 & DFC & 69 & 8 & S & F \\
\hline 633 & DFC & 39 & 8 & P & F \\
\hline 634 & DFC & 27 & 8 & S & F \\
\hline 430 & DHF & 25 & 6 & P & F \\
\hline 586 & DHF & 16 & 5 & S & F \\
\hline 557 & DHF & 76 & 9 & S & F \\
\hline 549 & DHF & 10 & 11 & S & F \\
\hline 543 & DHF & 29 & 11 & S & F \\
\hline 586 & DHF & 16 & 7 & S & F \\
\hline 414 & DHF & 34 & 5 & $?$ & M \\
\hline 277 & DHF & 41 & 9 & S & M \\
\hline COL1 & ND & 32 & - & - & M \\
\hline COL2 & ND & 38 & - & - & M \\
\hline COL3 & ND & 28 & - & - & F \\
\hline COL4 & ND & 30 & - & - & F \\
\hline COL5 & ND & 26 & - & - & F \\
\hline & & & & \\
\hline
\end{tabular}

$\mathrm{DPO}=$ days post onset of symptoms, $\mathrm{P}=$ primary infection, $\mathrm{S}=$ sequential infection, ? = not known. 


\section{Designing of Primers AND Probes}

Primer Express 2.0 software (Applied Biosystems, Foster City, CA, USA) was used to design sets of primers and probes. The design of six sets of primers and probes were performed following the same principle: only the mRNA should be amplified. To test the specificity of the primers, we performed conventional PCR assays using cDNA (400ng) obtained as described below, and also human genomic DNA (5ng - Invitrogen, Carlsbad, CA, USA) as control. The PCR reactions were made using the following parameters: $95^{\circ} \mathrm{C}-15 \mathrm{~s}, 58^{\circ} \mathrm{C}-60 \mathrm{~s}$, 40 cycles, and primers $2,5 \mu \mathrm{M}$.

\section{QUANTITATIVE REAL-TIME PCR}

Genes were amplified and detected using TaqMan ${ }^{\circledR}$ gene expression assays (Applied Biosystems, Foster City, CA, USA) with primers and probes designed as mentioned above. Total RNA was extracted using the RNeasy mini Kit (Qiagen, Valencia, CA, USA) and treated with DNAse (Qiagen, Valencia, CA, USA). Total RNA $(1 \mu \mathrm{g})$ was reversely transcribed to cDNA using SuperScript III First-strand Synthesis System (Invitrogen, Carlsbad, CA, USA) and random hexamer primers (Invitrogen, Carlsbad, CA, USA) following the reaction: $50^{\circ} \mathrm{C}$ for 30 minutes, $85^{\circ} \mathrm{C}$ for 5 minutes and chilled on ice. RNase $\mathrm{H}(2 \mathrm{U})$ (Invitrogen, Carlsbad, CA, USA) was added and samples were incubated at $37^{\circ} \mathrm{C}$ for 20 minutes. Quantitative real time PCR was carried out using the ABI PRISM 7500 device (Applied Biosystems, Foster City, CA, USA). Two mixes composed by eight DF/DFC or eight DHF cDNA samples were used as targets. A mix of five ND cDNA samples was used as a reference to DF and DHF results. $\beta$-Actin gene expression was used for the normalization of gene expression data due to the constitutive nature of its expression. The reactions were performed in triplicates and included $2 \mu 1$ of cDNA, primers $(20 \mu \mathrm{M}$ each) and $6.25 \mu \mathrm{M}$ of the specific probe, human Beta-Actin (Applied Biosystems, Foster City, CA, USA), TaqMan Universal PCR Master Mix (Applied Biosystems, Foster City, CA, USA) and water added to a final volume of $25 \mu \mathrm{l}$. Triplicates of non-template controls (NTC) were always included when qPCR was undertaken. Cycle conditions were as follows: after an initial 2-min hold at $50^{\circ} \mathrm{C}$ and 10 minutes at $95^{\circ} \mathrm{C}$, the samples were cycled 40 times at $95^{\circ} \mathrm{C}$ for $15 \mathrm{sec}$ and $60^{\circ} \mathrm{C}$ for $1 \mathrm{~min}$. Baseline and threshold for cycle threshold $(\mathrm{Ct})$ calculation were set automatically with Sequence Detection Software version 1.4 (Applied Biosystems, Foster City, CA, USA). The efficiency of amplification (E) of a target molecule was calculated from the slope of the standard curve (plot of $\mathrm{Ct}$ versus the negative $\log 10$ concentration of the target) derived from the slopes $\left(E=\left[10^{(-1 / \text { Slope })}\right]-1\right)$. For relative calculation, the $\Delta \Delta \mathrm{Ct}$ method was used (Livak and Schmittgen 2001, Applied Biosystems 7500/7500 Fast Real-Time PCR Systems - User Bulletin) once all assays met the amplification efficiency criteria of $100 \% \pm 10 \%$ (Applied Biosystems - Application Note 127AP05-02).

\section{RESULTS}

A set of primers were designed to specifically amplify the target genes from cDNA, but not from any contaminant genomic DNA in the samples. For this purpose, it was chosen the junction regions of exons from these genes and, for all of them, the primers or the probe was annealed in this region. To test the specificity of the primers, we performed conventional PCR using patient's extracted cDNA and human genomic DNA as control. In Figure 1 it is possible to notice unique bands with the expected molecular weight indicating that all the six sets of primers amplified correctly their respective genes. To test the primers ability to amplify genomic DNA, we used human genomic DNA in the same conditions of amplification. It is also possible to observe that none of the primers specifically amplifies genomic DNA.

To verify the influence of infection by DENV on the expression of tested genes, we performed qPCR assays using a pool composed by five cDNA samples of health individuals, and a pool composed by sixteen cDNA samples obtained from PBMCs of DF and DHF patients. All the genes tested, previously identified by microarray experiments, were up-regulated after infection of patients by DENV (Fig. 2). The mRNA of each patient was collected during the acute febrile phase of disease (Table I). Among the six genes, genes 4, 5 and 6 were the most highly expressed.

To test which genes could be used as putative "DHF molecular signatures", we performed qPCR ana- 


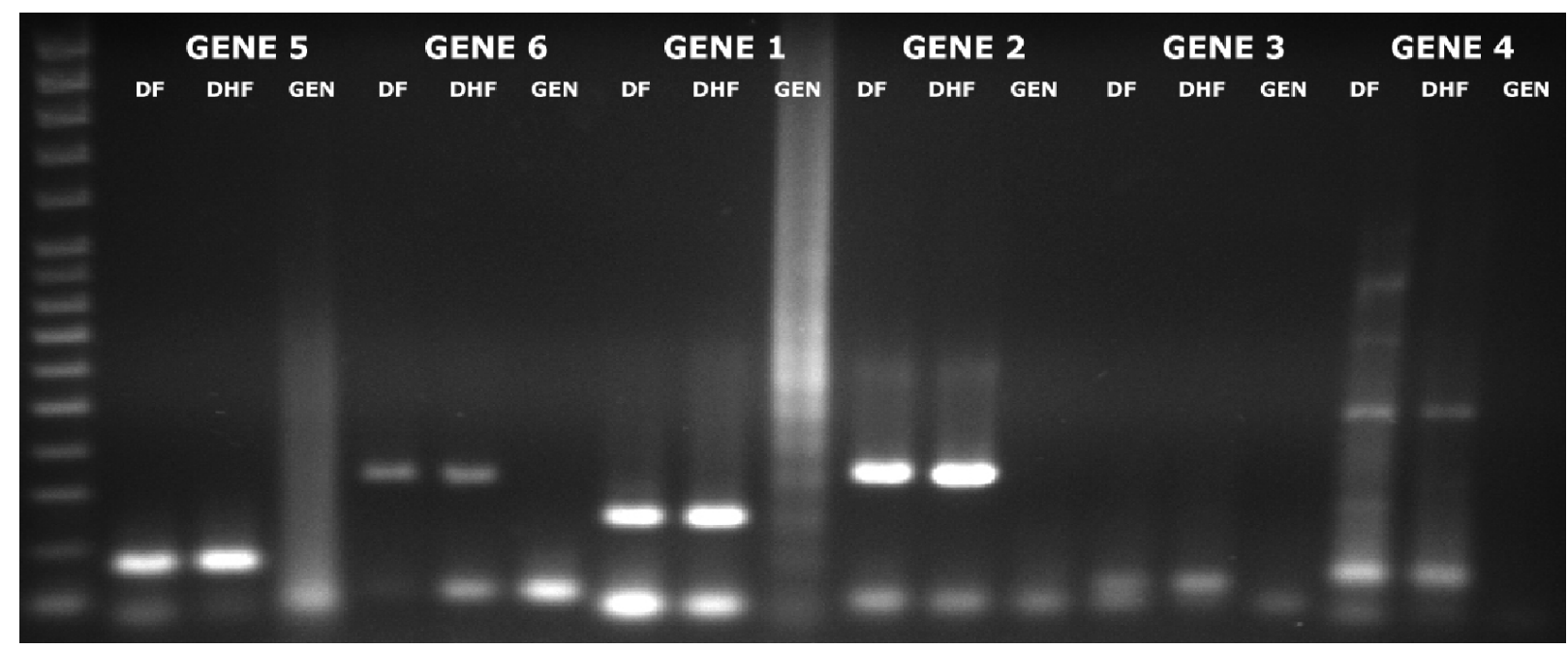

Fig. 1 - Specific amplification of the target genes in DF and DHF samples. DF $=\mathrm{cDNA}$ of dengue fever patients, DHF $=\mathrm{cDNA}$ of dengue hemorrhagic fever patients and GEN = human genomic DNA. Gene 5 (80 bp) Gene 6 (164 bp) Gene 1 (124 bp) Gene 2 (171 bp) Gene 3 (64 bp) Gene 4 (75 bp). Molecular weight marker 50 bp step ladder (Invitrogen, Carlsbad, USA).

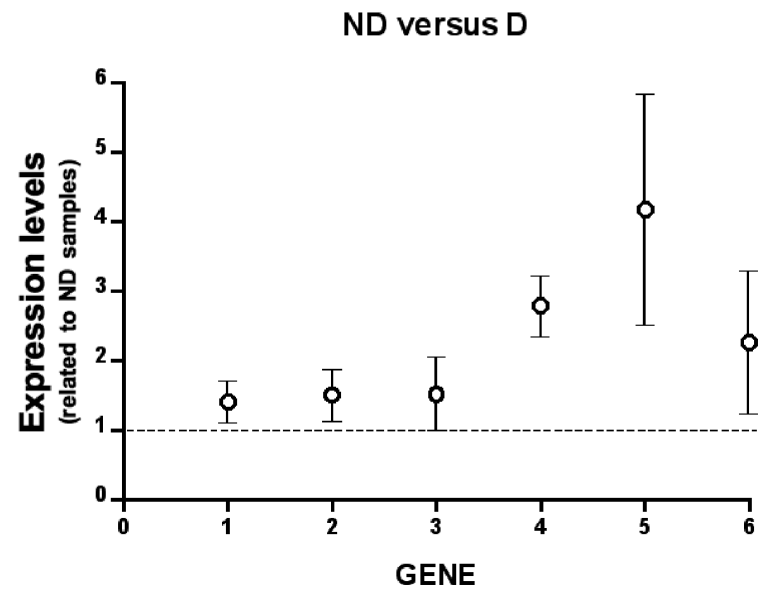

Fig. 2 - Comparison of the expression levels of the tested genes between health and dengue virus infected samples. A pool of sixteen (8 DF/DFC plus $8 \mathrm{DHF}$ ) dengue samples and a pool of five nondengue (ND) samples were used to extract mRNA. The amount of mRNA of each tested gene was measured by qPCR assays. Expression levels of tested genes are related to ND samples. All samples were tested in triplicates.

lyses using pools composed by cDNA of health individuals, or by cDNA of DF patients, or by cDNA of DHF patients. All of the six genes selected from the differentially expressed genes in DF and DHF patients confirmed to be potential candidates as "molecular signatures" to foresee DHF (Fig. 3). Gene 6 is more expressed in DHF patients, whereas the other genes showed the opposite behavior. Among the six tested candidates, apparently genes 3 to 6 showed better capacity to discriminate DF and DHF. Like genes 3 and 6 , gene 5 also shows a difference in its expression levels when comparing DHF and DF samples. It is interesting to note that gene 5 was the most expressed in DF samples among the tested genes.

\section{DISCUSSION}

Gene expression studies represent an opportunity to identify novel markers linked to immunity and disease pathogenesis, and an opportunity to classify patients with dengue in a manner that provides greater biological relevance and clinical utility (Fink et al. 2007).

Nowadays, one of the most relevant questions to scientists concerning dengue symptomatology is to determine which factors have influence on the development of DHF. It is a consensus that the severity of dengue is associated to multifactorial aspects like viral charge and serotype, sequential infections and genetics aspects of the host (Simmons et al. 2007).

The diagnostic techniques to detect and confirm the presence and serotype of DENV infecting a patient are very accurate, simple and satisfactorily fast. However, the current diagnostic techniques are unable to 


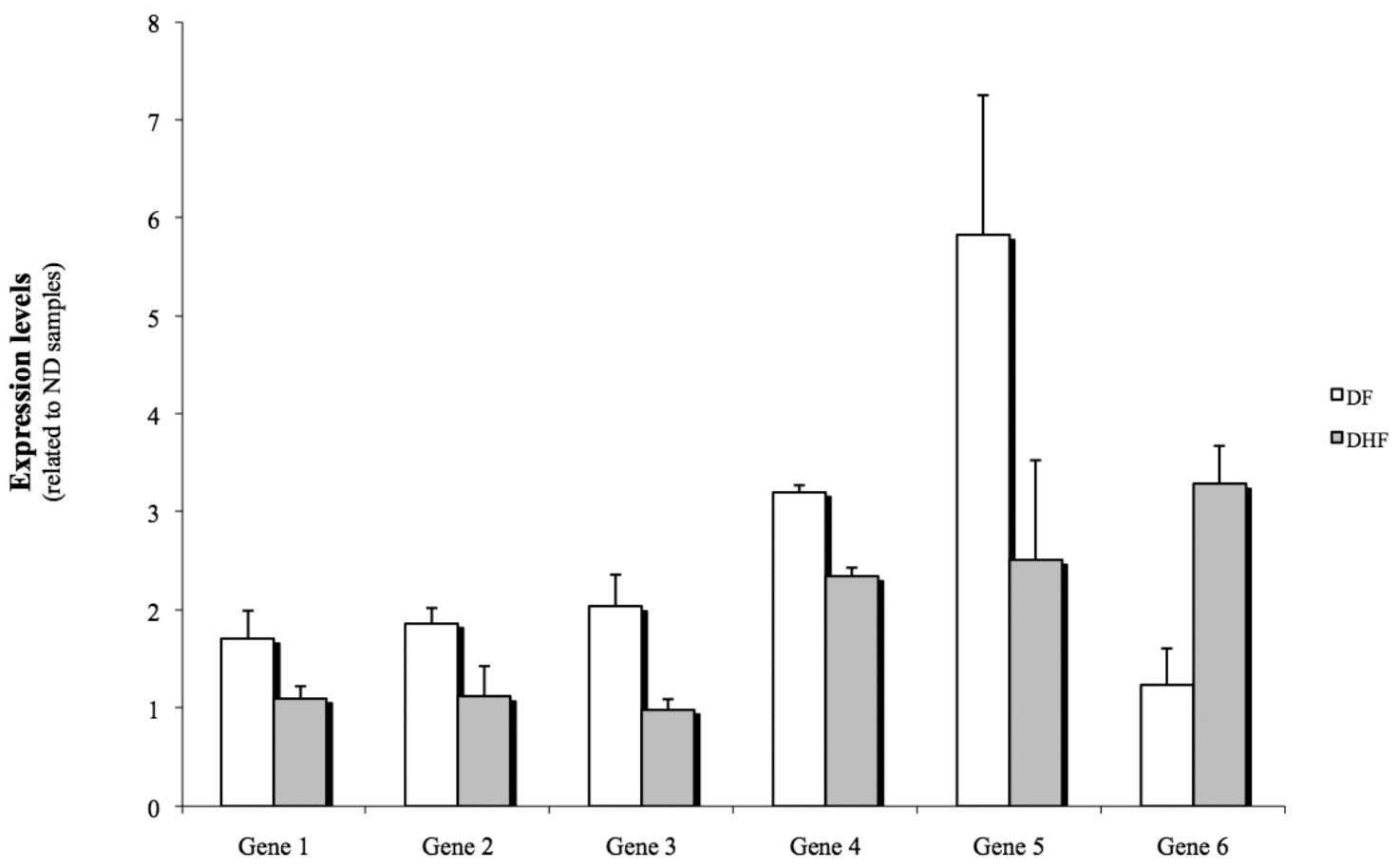

Fig. 3 - Expression levels of six genes in samples of patients with different clinical forms of dengue. The amount of mRNA of each tested gene was measured by qPCR assays using pools of eight DF/DFC or eight DHF cDNA samples as template. Expression levels are related to values obtained from pools of five ND samples. All samples were tested in triplicates. Data representative of three experiments to genes 1, 3, 4 and 5 and two experiments to genes 2 and 6 . All the differences were statistically significant $(\mathrm{p}<0.005)$.

predict the prognosis of DENV infected patients to develop the severe form of the disease.

Studies performed in cell lines or in patient's samples have been obliging to demonstrate gene expression associated with dengue infection. Kruif et al. (2008) showed the molecular basis of inflammatory gene expression patterns in peripheral blood leukocytes from children with severe dengue infection. It was demonstrated significant differences in gene expression patterns between DF PBMCs and DHF PBMCs during the acute phase of the infection.

In this work, we used a set of primers specifically designed to amplify cDNA, obtained from PBMC of DF and DHF patients, codifying for six genes involved on innate immune responses, previously identified by microarray approach, whose expression levels were different between the classical and severe forms of the disease (E.J. Nascimento et al., unpublished data).

As shown in Figure 2, all tested genes had its expression levels under influence of DENV infection. It has been shown a strong association between a decreased innate immune response and increased apoptosis levels with the development of DHF (Kruif et al. 2008, Ubol et al. 2008, Simmons et al. 2007, Chaturvedi et al. 2006). Corroborating our data, the only gene more expressed in DHF samples was gene 6 (Fig. 3), a pro-apoptotic gene. Gene 6 is almost 4-fold more expressed in dengue than in non-dengue samples. Otherwise, all the other five genes tested, involved on innate immune responses, were up regulated in DHF patients.

The involvement of apoptosis on the developing of severe symptoms noticed in DHF was earlier studied by Mongkolsapaya et al. (2003), when they recovered few dengue-responsive $\mathrm{CD} 8+\mathrm{T}$ cells in Thai children during acute phase of disease; most of those undergoing programmed cell death. In fact, during the last years, the correlation between the apoptosis process and hemorrhagic manifestations noticed in severe dengue has been established (Myint et al. 2006, Mosquera et al. 2005, Espina et al. 2003). 
In our study, gene 5, which is more directly involved on innate immune responses, since its product codify for a receptor to the Fc portion (FcR) of immunoglobulin, was the most down regulated in DHF samples among the five tested genes, corroborating the findings of other research groups (Kruif et al. 2008, Ubol et al. 2008, Simmons et al. 2007, Chaturvedi et al. 2006). However, the expression levels of gene 5 presented the highest standard deviation values, indicating that the level of expression of this gene could be very variable among patients and, consequently, inappropriate do be used alone as "DHF molecular signature".

Recently, Brown et al. (2009) had demonstrated that antibody-enhanced dengue virus infection of the FcR-bearing mast cell/basophil KU812 cell line results in a massive induction of caspase-dependent apoptosis. This find corroborates the relationship of the expression levels of genes 5 and 6.

The qPCR assay results indicates that the quantification of those genes in samples collected during the early symptoms of a dengue infected patient could be useful on the prognosis of DHF development. The identification of a group of genes with potential to be used as molecular signatures of DHF development can become a confident tool, valuable in helping on DHF clinical diagnosis. Our results suggest that it is possible to define the genes that are differentially expressed between DF and DHF patients during the initial moments of the onset of symptoms and, consequently, predict the propensity of a dengue patient to evolve to the severe form of the disease. However, it is necessary to increase the number of samples to statistically determine the reliability limits of these results.

Nowadays we are collecting more samples of dengue-infected patients in the acute phase of the disease to reinforce data presented here and also to be used on tests of predictive value, specificity and sensibility. Moreover, we are selecting other genes to be tested aiming to define the best panel of "DHF molecular signature genes".

\section{ACKNOWLEDGMENTS}

The authors thank the financial support of the Strategic Program of Support to Health Research - PAPES-FIOCRUZ (403539/2008-0), National Institute of Health
- NIH (U19 AI56541), and the Conselho Nacional de Desenvolvimento Científico e Tecnológico (CNPq) (472939/2007-6). The authors also thank the Program for Technological Development in Tools for Health PDTIS RVR09 - FIOCRUZ for the use of its facilities.

\section{RESUMO}

O manejo de pacientes infectados pelo dengue ainda é um problema desafiador. A maioria dos casos de dengue é benigna mas parte desses casos pode evoluir para o desenvolvimento de vasculopatia severa conhecida como dengue hemorrágica, que pode ser letal. Os sintomas iniciais da dengue e sua forma hemorrágica são bastante similares. O desenvolvimento de um teste diagnóstico que seja rápido e capaz de diferenciar as duas formas clínicas da dengue é crucial para o cuidado adequado de pacientes. O presente estudo avalia, através da PCR quantitativa em tempo real, o potencial preditivo dos níveis de expressão de RNAm candidatos a marcadores da dengue hemorrágica, previamente identificados por estudos genômicos funcionais. Um conjunto de seis marcadores moleculares para a dengue hemorrágica foi avaliado e apresentou correlação entre seus níveis de transcrição e o posterior desenvolvimento da vasculopatia severa. Os marcadores selecionados foram capazes de indicar, nos momentos iniciais dos sintomas, a evolução de um paciente infectado pelo dengue para a forma severa da doença. O painel de candidatos a marcadores de prognóstico obtido demonstrou um bom potencial para uso clínico na forma de um ensaios rápido baseado em amostras de sangue.

Palavras-chave: PCR em tempo real, dengue hemorrágica, marcadores moleculares.

\section{REFERENCES}

Applied Biosystems 7500/7500. 2008. Fast Real-Time PCR Systems - User Bulletin.

http://www3.appliedbiosystems.com/cms/groups/mcb_support/ documents/generaldocuments/cms_050637.pdf.

Applied Biosystems - Application Note 127AP0502. 2006.

http://ifr31.toulouse.inserm.fr/PFT/BM/mediabm/22.pdf.

Bente DA AND Rico-Hesse R. 2006. Models of dengue virus infection. Drug Discov Today Dis Models 3: $97-$ 103.

Brown MG, Huang YY, Marshall JS, King CA, Hoskin DW And Anderson R. 2009. Dramatic caspase-dependent apoptosis in antibody-enhanced dengue 
virus infection of human mast cells. J Leukoc Biol 85: 71-80.

Chaturvedi UC, Nagar R and Shrivastava R. 2006 Dengue and dengue hemorrhagic fever: implications of host genetics. FEMS Microbiol Lett 47: 155-166.

Cordeiro MT, Silva AM, Brito CA, NAscimento EJ, Magalhães MC, Guimarães GF, Lucena-Silva N, de Carvalho EM and Marques ET JR. 2007. Characterization of a Dengue Patient Cohort in Recife, Brazil. Am J Trop Med Hyg 77: 1128-1134.

Espina LM, VAlero NJ, Hernández JM and MosQUERA JA. 2003. Increased apoptosis and expression of tumor necrosis factor-alpha caused by infection of cultured human monocytes with dengue virus. Am J Trop Med Hyg 68: 48-53.

FINK J ET AL. 2007. Host Gene Expression Profiling of Dengue Virus Infection in Cell Lines and Patients. PLoS Negl Trop Dis 1(2): e86.

Halstead SB, Rojanasuphot S and SangKawibha N. 1983. Original antigenic sin in dengue. Am J Trop Med Hyg 32: 154-156.

Halstead SB. 2007. Dengue. Lancet 370: 1644-1652.

KRUIF MD ET AL. 2008. Differential Gene Expression Changes in Children with Severe Dengue Virus Infections. PLoS Negl Trop Dis 2: e215.

LEE YR, LiU MT, LeI HY, LiU CC, Wu JM, Tung YC, LIN YS, YeH TM, CHEN SH AND LIU HS. 2006. MCP1 , a highly expressed chemokine in dengue haemorrhagic fever/dengue shock syndrome patients may cause permeability change, possibly through reduced tight junctions of vascular endothelium cells. J Gen Virol 87: $3623-3630$.
Livak KJ AND Schmittgen TD. 2001. Analysis of Relative Gene Expression Data Using Real-Time Quantitative PCR and the $2^{-\delta}$ delta CT Method. Methods 25: 402-408.

MONGKolsapaya J ET AL. 2003. Original antigenic sin and apoptosis in the pathogenesis of dengue hemorrhagic fever. Nat Med 9: 921-927.

Mosquera JA, Hernandez JP, Valero N, Espina LM AND AÑEZ GJ. 2005. Ultrastructural studies on dengue virus type 2 infection of cultured human monocytes. Virol J 2: 26 .

MYINT KS ET AL. 2006. Cellular immune activation in children with acute dengue virus infections is modulated by apoptosis. J Infect Dis 194(5): 600-607. Epub 2006 Jul 31.

SANCHes EN, Després P AND Cedillo-BARRón L. 2005. Innate Immune Response to Dengue Virus. Arch Med Res 36: 425-435.

Shu PY And Huang JH. 2004. Current Advances in Dengue Diagnosis. Clin Diagn Lab Immunol 11: 642 650 .

Simmons CP ET AL. 2007. Patterns of Host Genome-Wide Gene Transcript Abundance in the Peripheral Blood of Patients with Acute Dengue Hemorrhagic Fever. J Infect Dis 195: $1097-1107$.

Ubol S, Masrinoul P, Chaijaruwanich J, KalayaNAROOJ S, CHAROENSIRISUTHIKUL T AND KASISITH J. 2008. Differences in Global Gene Expression in peripheral Blood Mononuclear Cells Indicate a Significant Role of the Innate Responses in Progression of Dengue Fever but Not Dengue Hemorrhagic Fever. J Infect Dis 197: 1459-1467. 